\title{
Computed tomography-based validation of abdominal adiposity measurements from ultrasonography, dual-energy X-ray absorptiometry and anthropometry
}

\author{
Anna M. I. Gradmark ${ }^{1}$, Anders Rydh ${ }^{2}$, Frida Renström ${ }^{1}$, Emanuella De Lucia-Rolfe ${ }^{3}$, Alison Sleigh ${ }^{4}$, \\ Peter Nordström ${ }^{5}$, Soren Brage ${ }^{3}$ and Paul W. Franks ${ }^{1 *}$ \\ ${ }^{1}$ Genetic Epidemiology and Clinical Research Group, Department of Public Health and Clinical Medicine, Division of Medicine, \\ Umeå University Hospital, Umeå 90 187, Sweden \\ ${ }^{2}$ Department of Radiology, Umeå University Hospital, Umeå, Sweden \\ ${ }^{3}$ MRC Epidemiology Unit, Institute of Metabolic Science, Cambridge, UK \\ ${ }^{4}$ Wolfson Brain Imaging Centre, Addenbrooke's Hospital, Cambridge, UK \\ ${ }^{5}$ Department of Surgery and Perioperative Sciences, Umeå University Hospital, Umeå, Sweden
}

(Received 19 October 2009 - Revised 4 February 2010 - Accepted 9 February 2010 - First published online 7 April 2010)

\begin{abstract}
Large-scale aetiological studies of obesity and its pathological consequences require accurate measurements of adipose mass, distribution and subtype. Here, we compared the validity of three abdominal obesity assessment methods (dual-energy X-ray absorptiometry (DXA), ultrasound and anthropometry) against the gold-standard method of computed tomography (CT) in twenty-nine non-diseased middle-aged men (BMI $26 \cdot 5$ $($ SD $3 \cdot 1) \mathrm{kg} / \mathrm{m}^{2}$ ) and women (BMI $25 \cdot 5(\mathrm{SD} 3 \cdot 2) \mathrm{kg} / \mathrm{m}^{2}$ ). Assessments of adipose mass (kg) and distribution (total subcutaneous (TSAT), superficial subcutaneous (SSAT), deep subcutaneous (DSAT) and visceral (VAT)) were obtained. Spearman's correlations were performed adjusted for age and sex. VAT area that was assessed using ultrasound $(r 0.79 ; P<0.0001)$ and waist circumference $(r 0.85 ; P<0.0001)$ correlated highly with VAT from CT, as did BMI $(r$ 0.67; $P<0.0001)$ and DXA $(r \quad 0.70 ; P<0.0001)$. DXA $(r \quad 0.72 ; P=0 \cdot 0004)$, BMI $(r \quad 0.71$; $P=0.0003)$, waist circumference $(r 0.86 ; P<0.0001)$ and ultrasound $(r 0.52 ; P=0.015)$ were less strongly correlated with CT TSAT. None of the comparison measures of DSAT was strongly correlated with CT DSAT (all $r$ approximately 0.50; $P<0.02)$. BMI $(r$ 0.76; $P<0.0001)$, waist circumference $(r 0.65 ; P=0.002)$ and DXA $(r 0.75 ; P<0.0001)$ were all fairly strongly correlated with the CT measure of SSAT, whereas ultrasound yielded a weaker yet statistically significant correlation $(r 0.48 ; P=0.03)$. Compared with CT, visceral and subcutaneous adiposity can be assessed with reasonable validity using waist circumference and BMI, respectively. Ultrasound or DXA does not generally provide substantially better measures of these traits. Highly valid assessments of DSAT do not appear to be possible with surrogate measures. These findings may help guide the selection of measures for epidemiological studies of obesity.
\end{abstract}

Computed tomography: Ultrasound: Waist circumference: Waist:height ratio: Dual-energy X-ray absorptiometry: Obesity: Adipose tissue: Validation

An abundance of adipose tissue is an established risk factor for CVD, type 2 diabetes, sleep apnoea, osteoarthritis, certain cancers, depression and early death ${ }^{(1)}$. Several studies have suggested that the superficial and deep subcutaneous adipose compartments have different metabolic properties ${ }^{(2-5)}$. The methods available to measure abdominal adiposity vary in feasibility and economic cost, factors which are often used to justify the choice of methods in research studies. Although anthropometric methods are frequently used to assess body composition in epidemiological studies, several scanning-based methods are available which may be suitable for use in the epidemiological setting. These include dual-energy X-ray absorptiometry (DXA) and ultrasonography; the latter can be performed with mobile equipment and is non-invasive.

Although studies exist where ultrasound and DXA have been validated for the assessment of adipose mass and distribution $^{(6-13)}$, to our knowledge, no studies have been reported where the validity of ultrasound for the assessment of deep and superficial subcutaneous adipose tissue (SAT) has been ascertained and compared with DXA or computed tomography (CT).

The purpose of the present study was to compare three body composition assessment methods (ultrasound, DXA and anthropometry) against the gold-standard method of CT.

Abbreviations: CT, computed tomography; DXA, dual-energy X-ray absorptiometry; SAT, subcutaneous adipose tissue; VAT, visceral adipose tissue. 


\section{Participants and methods}

Participants were white middle-aged men $(n 16)$ and women ( $n$ 13) from the county of Västerbotten in northern Sweden. Measurements were conducted at the Clinical Research Center and Department of Radiology at the University Hospital. Before the initiation of the study protocol, the procedures and associated risks were explained in detail, and then all participants provided written informed consent. The study was conducted according to the guidelines laid down in the Declaration of Helsinki, and all procedures involving human subjects were approved by the Umeå Research Ethics Committee.

\section{Anthropometry}

Height to the nearest $0.1 \mathrm{~cm}$ and weight to the nearest $0.1 \mathrm{~kg}$ were measured using a calibrated wall-mounted stadiometer and digital scale, respectively, with participants wearing indoor clothing and no shoes. BMI was computed as weight $(\mathrm{kg})$ divided by the square of height $\left(\mathrm{m}^{2}\right)$. Waist circumference was measured to the nearest $0.1 \mathrm{~cm}$ in duplicate using a non-stretchable, retractable nylon tape at the midpoint between the twelfth rib and the iliac crest. Waist:height ratio was calculated as waist divided by height. For all anthropometric measures, the mean of the duplicate measures was used in the analyses.

\section{Body scans}

Participants wore light clothing, free from metallic parts and lay face-up, with their arms placed alongside the body. Measurements of body composition were done using DXA (Lunar Prodigy IV, GE Lunar, WI, USA), ultrasound (Acuson Sequoia, Siemens, Mountain Woods, CA, USA) and CT (Light Speed VCT, General Electric, Milwaukee, WI, USA) scanners calibrated daily according to the manufacturer's protocols. To reduce operator bias, the ultrasound, CT and DXA measurements were performed by operators who were blind to the results from other aspects of the study.

Computed tomography and ultrasound. Greyscale ultrasound images were obtained at lumbar $2-3$ by a clinical radiologist (A. R.), while the participants lay on their back and held their breath during mid-inspiration (Fig. 1(a)-(c)). For the assessment of SAT from ultrasound, a highresolution linear probe $(5-8 \mathrm{MHz})$ was used, whereas a convex probe $(1-4 \mathrm{MHz})$ was used for measuring visceral adipose tissue (VAT). When measuring SAT, the probe was placed $5 \mathrm{~cm}$ cranial to the umbilicus. Total SAT was measured from the posterior line of dermis to the outer bowel wall. Superficial SAT was measured as the distance between the posterior line of dermis to the fascia superficialis. The deep SAT compartment was determined as the distance between the fascia and the anterior line of the rectus abdominis muscle. VAT was assessed by measuring the distance from the inside of the bowel wall to the spine. SAT is located directly beneath the skin between the dermis and fascia, whereas VAT localises to the peritoneal cavity and surrounds various organs.
When scans were performed, minimal pressure was applied to the probe to avoid displacement of the abdominal cavity. Immediately after the ultrasound scan, a single CT scan was performed at the exact location indicated during the ultrasound examination (Fig. 1(a)-(c)). This spot was marked with an angiography catheter placed on the skin. CT images were obtained in the same position as the ultrasound scans by a different radiographer who was also blind to the results of the scans. Distances $(\mathrm{cm})$ were calculated on the CT and ultrasound scan images using a PACS workstation (SECTRA, Linköping, Sweden).

An upper and lower attenuation range for fat was set at -200 and -20 Hounsfield units, respectively ${ }^{(14)}$. The CT images were then thresholded at this fixed attenuation range using Analyze 7.0 (Biomedical Imaging Resource, Mayo Clinic, Rochester, MN, USA), such that all pixels sampled afterwards were those representing adipose tissue. Following extraction of the spine and posterior muscles, a region of interest was drawn that traced the transverse fascia between the abdominal cavity to provide a region that encompassed all VAT. Segmentation of the SAT into deep and superficial fat was performed manually using the methods outlined

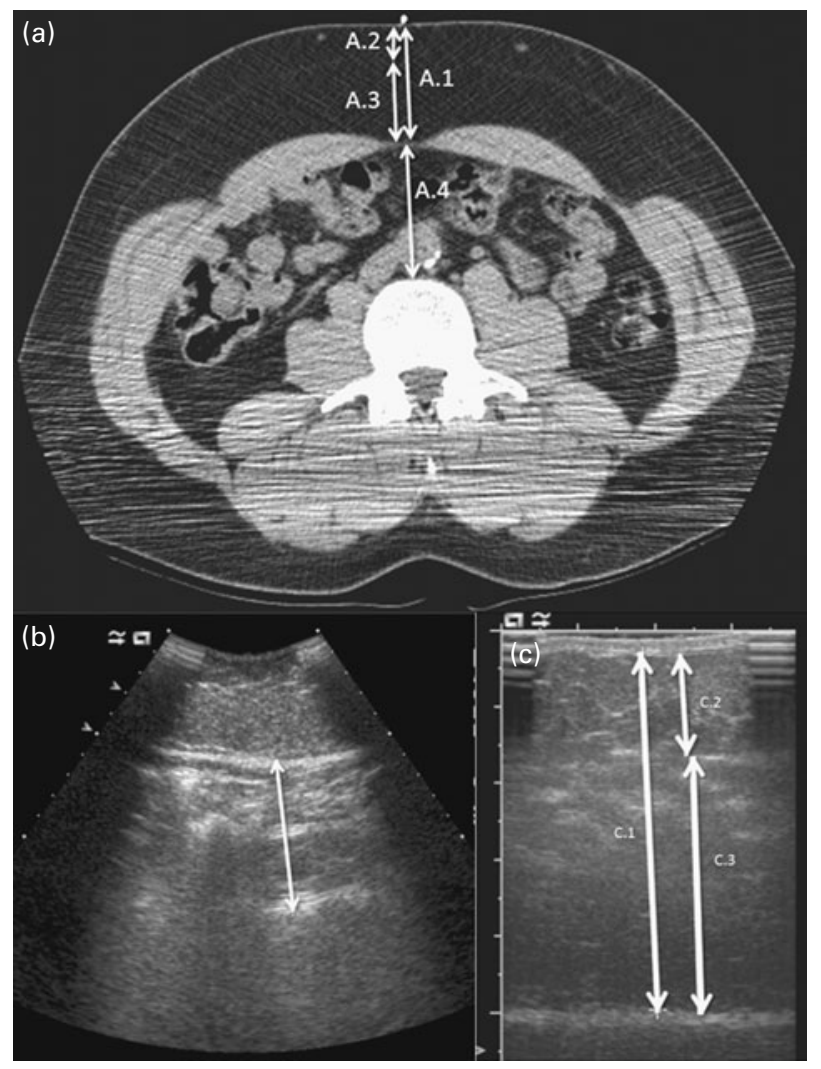

Fig. 1. Examples of the different computed tomography (CT) and ultrasound measurements. Panel (a) shows how measurements were made for the CT reference thicknesses; line A.1 shows the total subcutaneous thickness, line A. 2 shows the superficial subcutaneous thickness, line A. 3 shows the deep subcutaneous thickness and line A.4 shows the total visceral thickness. CT area calculations are defined in the Methods section. In panel (b), the line shows the total visceral thickness from ultrasound. In panel (c), line C.1 shows the total subcutaneous thickness, and lines C.2 and C.3 show the superficial and deep subcutaneous thicknesses, respectively. 
above. Where the distinction between deep and superficial adipose tissue was indeterminable, the total subcutaneous compartment was recorded. The area for each adipose compartment (i.e. visceral, and total, deep and superficial subcutaneous) was calculated from the number of pixels in the threshold map within each of these compartments.

The abdominal region for thirteen participants extended slightly beyond the CT camera field of view. To account for the missing area, the peripheral subcutaneous region was included for at least one side of the body, and this information was used to estimate the area of the missing region within the same individual, with the assumption that subcutaneous fat distribution is symmetrical at the level of the abdomen. This method has been shown to be valid when using DXA scans performed in morbidly obese persons ${ }^{(15)}$.

Dual-energy X-ray absorptiometry scans. The DXA scans were performed using a GE-Lunar Prodigy DEXA Scanner. Adipose areas were defined using the region of interest programme as described previously ${ }^{(16)}$.

All measurements were performed on the same day, and participants fasted before undergoing the scans. None of the study participants was on weight-loss prescription medications. As with most Western populations, dieting is common in Sweden; thus, it is possible that some of our participants may have been dieting at the time of the study. However, we did not collect such information.

\section{Statistical analysis}

Analyses were performed using the Statistical Analysis Systems software v9.1 (SAS Institute, Cary, NC, USA).
Correlations between pairs of variables were calculated using Spearman's rank order statistic $(r)$ for the comparisons involving measures with different scales, and Lin's concordance correlation $(\rho)$ was used for pairs of variables with the same scales (i.e. CT adipose distances $v$. US adipose distances). Generalised linear models were used to derive $\beta$-coefficients, and to calculate explained variances $\left(R^{2}\right)$. All analyses were adjusted for age and sex. Agreement between ultrasound and CT measures on the same scale was assessed using the Bland-Altman technique ${ }^{(17)}$. A $P$ value $<0.05$ was considered statistically significant.

\section{Results}

Participant characteristics are shown in Table 1 for men and women separately.

We initially tested whether any associations differed in magnitude by sex by fitting interaction terms ( $\operatorname{sex} \times$ each independent variable) to linear regression models. None of these terms was significant $(P>0 \cdot 1)$; therefore, remaining analyses were conducted in men and women combined, adjusted for age and sex (Tables 2 and 3 ).

\section{Comparisons against computed tomography-derived adipose areas $\left(\mathrm{cm}^{2}\right)$}

Subcutaneous adipose tissue. As shown in Table 2, waist circumference $(r$ 0.86; $P<0 \cdot 0001)$, waist:height ratio $(r$ 0.74; $P<0.0001)$, DXA total adipose mass $(\mathrm{kg})(r 0.72 ; P=0.0004)$ and BMI $(r 0.71 ; P=0.0003)$ were strongly and comparably correlated with CT total subcutaneous adipose tissue. The ultrasound measure of total subcutaneous adipose tissue was the

Table 1. Participant characteristics

(Mean values and standard deviations with their ranges)

\begin{tabular}{|c|c|c|c|c|c|c|c|c|c|}
\hline & \multicolumn{4}{|c|}{ Women $(n$ 13) } & \multicolumn{4}{|c|}{ Men $(n 16)$} & \multirow[b]{3}{*}{$P$-comparison* } \\
\hline & \multirow[b]{2}{*}{ Mean } & \multirow[b]{2}{*}{ SD } & \multicolumn{2}{|c|}{ Range } & \multirow[b]{2}{*}{ Mean } & \multirow[b]{2}{*}{ SD } & \multicolumn{2}{|c|}{ Range } & \\
\hline & & & Min & Max & & & Min & Max & \\
\hline \multicolumn{10}{|l|}{ Variable } \\
\hline Age (years) & $53 \cdot 0$ & $8 \cdot 6$ & $42 \cdot 2$ & $62 \cdot 5$ & $49 \cdot 1$ & $7 \cdot 9$ & 41.9 & $62 \cdot 3$ & 0.21 \\
\hline Height $(m)$ & 1.65 & 0.04 & 1.59 & 1.72 & 1.82 & 0.05 & 1.75 & 1.92 & 0.0001 \\
\hline Weight (kg) & $68 \cdot 7$ & $8 \cdot 5$ & $53 \cdot 0$ & $82 \cdot 0$ & $87 \cdot 5$ & $10 \cdot 0$ & $72 \cdot 4$ & $107 \cdot 0$ & 0.0001 \\
\hline $\operatorname{BMI}\left(\mathrm{kg} / \mathrm{m}^{2}\right)$ & $25 \cdot 5$ & $3 \cdot 2$ & $21 \cdot 4$ & $32 \cdot 0$ & $26 \cdot 5$ & $3 \cdot 1$ & $21 \cdot 3$ & $32 \cdot 0$ & 0.41 \\
\hline Waist circumference $(\mathrm{cm})$ & $84 \cdot 7$ & $9 \cdot 2$ & $75 \cdot 0$ & $100 \cdot 0$ & $94 \cdot 1$ & 7.5 & $84 \cdot 0$ & $107 \cdot 0$ & 0.005 \\
\hline Waist:height ratio & 0.31 & 0.03 & 0.28 & 0.38 & 0.29 & 0.03 & 0.24 & 0.34 & 0.02 \\
\hline CT visceral $\left(\mathrm{cm}^{2}\right)$ & $120 \cdot 4$ & $61 \cdot 5$ & 42.9 & $225 \cdot 8$ & $165 \cdot 7$ & 89.5 & $57 \cdot 3$ & $327 \cdot 4$ & $0 \cdot 14$ \\
\hline $\mathrm{CT}$ total subcutaneous $\left(\mathrm{cm}^{2}\right)$ & 243.0 & 78.5 & $125 \cdot 2$ & 388.4 & $187 \cdot 0$ & $62 \cdot 6$ & $120 \cdot 7$ & $325 \cdot 2$ & 0.05 \\
\hline CT superficial subcutaneous $\left(\mathrm{cm}^{2}\right)$ & $146 \cdot 5$ & $50 \cdot 0$ & $81 \cdot 2$ & $254 \cdot 0$ & 103.5 & 33.7 & $69 \cdot 0$ & $175 \cdot 9$ & 0.03 \\
\hline CT deep subcutaneous $\left(\mathrm{cm}^{2}\right)$ & $97 \cdot 0$ & $37 \cdot 6$ & $44 \cdot 0$ & $158 \cdot 9$ & 73.8 & $30 \cdot 6$ & $41 \cdot 2$ & $149 \cdot 4$ & 0.12 \\
\hline CT visceral $(\mathrm{cm})$ & 6.97 & $2 \cdot 01$ & 3.30 & $10 \cdot 81$ & 8.47 & $2 \cdot 38$ & 5.06 & 11.84 & 0.08 \\
\hline CT total subcutaneous $(\mathrm{cm})$ & 3.03 & 0.92 & 1.83 & 4.43 & $2 \cdot 76$ & 1.05 & 1.69 & $5 \cdot 20$ & 0.47 \\
\hline CT superficial subcutaneous $(\mathrm{cm})$ & 1.53 & 0.49 & $1 \cdot 13$ & $2 \cdot 44$ & 1.07 & 0.33 & 0.63 & 1.83 & 0.01 \\
\hline CT deep subcutaneous $(\mathrm{cm})$ & 1.61 & 0.70 & 0.63 & $2 \cdot 67$ & 1.75 & 0.76 & 0.92 & 3.73 & 0.64 \\
\hline Ultrasound visceral (cm) & $6 \cdot 77$ & 1.49 & 3.96 & $9 \cdot 56$ & $7 \cdot 88$ & $2 \cdot 14$ & 4.98 & 11.34 & $0 \cdot 13$ \\
\hline Ultrasound total subcutaneous $(\mathrm{cm})$ & $2 \cdot 95$ & 0.88 & 1.77 & 4.52 & $2 \cdot 89$ & 0.97 & 1.96 & $4 \cdot 81$ & 0.87 \\
\hline Ultrasound superficial subcutaneous $(\mathrm{cm})$ & 1.54 & 0.48 & 0.81 & $2 \cdot 33$ & 1.23 & $0 \cdot 13$ & 0.95 & 1.48 & 0.04 \\
\hline Ultrasound deep subcutaneous $(\mathrm{cm})$ & 1.73 & 0.63 & 0.54 & $2 \cdot 70$ & 1.65 & 0.94 & 0.66 & 3.48 & 0.79 \\
\hline DXA abdominal adipose $(\mathrm{kg})$ & 1.75 & 0.69 & $0 \cdot 81$ & $2 \cdot 71$ & 2.07 & 0.78 & 0.88 & $3 \cdot 13$ & $<0.0001$ \\
\hline DXA total adipose $(\mathrm{kg})$ & $25 \cdot 9$ & $8 \cdot 1$ & $14 \cdot 6$ & $40 \cdot 5$ & $22 \cdot 4$ & $6 \cdot 9$ & 11.0 & $31 \cdot 1$ & 0.21 \\
\hline
\end{tabular}

Min, minimum; Max, maximum; CT, computed tomography; DXA, dual-energy X-ray absorptiometry.

${ }^{*} P$ values for the comparison of men and women using an independent (two-side) Student's $t$ test. Ultrasound scans were performed in only twenty-two participants. 
Table 2. Spearman's correlation coefficients for ultrasound, dual-energy X-ray absorptiometry (DXA) and anthropometric measures of adiposity compared with computed tomography (CT) measures of adipose areas $(n 22)$

\begin{tabular}{|c|c|c|c|c|}
\hline & \multicolumn{4}{|c|}{ CT measure } \\
\hline & $\begin{array}{l}\text { Visceral } \\
\left(\mathrm{cm}^{2}\right)\end{array}$ & $\begin{array}{l}\text { Subcutaneous } \\
\text { (total, } \mathrm{cm}^{2} \text { ) }\end{array}$ & $\begin{array}{l}\text { Subcutaneous } \\
\text { (superficial, } \mathrm{cm}^{2} \text { ) }\end{array}$ & $\begin{array}{c}\text { Subcutaneous } \\
\left.\text { (deep, } \mathrm{cm}^{2}\right)\end{array}$ \\
\hline \multicolumn{5}{|l|}{ Comparative measure } \\
\hline $\mathrm{BMI}\left(\mathrm{kg} / \mathrm{m}^{2}\right)$ & $0.67^{\star \star \star}$ & $0.71^{* * *}$ & $0.76^{\star * * *} \dagger$ & $0.53^{*}$ \\
\hline Waist circumference $(\mathrm{cm})$ & $0.85^{\star \star \star \star} \dagger$ & $0.86^{\star \star \star \star} \dagger$ & $0.65^{\star \star}$ & $0.54^{\star}$ \\
\hline Waist:height ratio & $0 \cdot 81^{\star \star \star \star}$ & $0.74^{\star \star \star}$ & $0.69^{\star \star *}$ & $0.66^{\star *} \dagger$ \\
\hline Ultrasound visceral (cm) & $0.79^{\star \star \star \star}$ & $0.54^{\star}$ & $0.56^{\star \star}$ & 0.43 \\
\hline Ultrasound subcutaneous (total, $\mathrm{cm}$ ) & 0.24 & $0.52^{*}$ & $0.47^{*}$ & $0.40^{\star}$ \\
\hline Ultrasound subcutaneous (superficial, $\mathrm{cm}$ ) & $0.62^{\star \star}$ & $0.49^{*}$ & $0.48^{*}$ & 0.36 \\
\hline Ultrasound subcutaneous (deep, cm) & 0.15 & $0.51^{*}$ & $0.47^{\star}$ & $0.49^{\star}$ \\
\hline DXA (abdominal fat, kg) & $0.72^{\star \star \star}$ & $0.58^{\star *}$ & $0.73^{\star \star \star}$ & $0.51^{*}$ \\
\hline DXA (total fat mass, $\mathrm{kg}$ ) & $0.70^{\star \star \star}$ & $0.72^{\star \star \star}$ & $0.75^{\star \star \star \star}$ & $0.50^{\star}$ \\
\hline
\end{tabular}

weakest correlate of the CT measure, although this relationship was statistically significant $(r 0 \cdot 52 ; P=0 \cdot 015)$.

Most comparison measures of deep subcutaneous adipose tissue were generally weakly correlated with the CT deep subcutaneous adipose tissue measure, although all were statistically significant (all $r$ approximately $0.50 ; P<0.02$ ). The exception was waist:height ratio, which yielded a fairly strong correlation with CT deep subcutaneous adipose tissue ( $r$ 0.66; $P=0.002)$.

BMI $(r \quad 0.76 ; P<0.0001)$, waist:height ratio $(r \quad 0.69$; $P=0.0001)$, waist circumference $(r 0.65 ; P=0.002)$ and DXA $(r 0.75 ; P<0.0001)$ were all fairly strongly correlated with the CT measure of superficial subcutaneous adipose tissue, whereas ultrasound yielded a weaker, yet statistically significant, correlation ( $r 0.48 ; P=0.03$ ).

Visceral adipose tissue. VAT assessed using ultrasound ( $r 0.79 ; P<0.0001)$, waist circumference $(r 0.85 ; P<0.0001)$ and waist:height ratio $(r 0.81 ; P<0.0001)$ was strongly correlated with VAT from CT. BMI $(r 0.67 ; P<0.0001)$ and DXA $(\mathrm{kg})(r 0.70 ; P<0.0001)$ were also strong correlates of the CT-derived measure of VAT.

\section{Comparisons of ultrasound and computed tomography adipose thicknesses $(\mathrm{cm})$}

Here, we present the correlations for adipose thicknesses as this is the most direct comparison of methods when comparing CT and ultrasound, and may be of value for studies focused specifically on adipose thickness (e.g. surgical interventions). These results also illustrate the extent to which comparisons of thicknesses might lead to an overestimation of the magnitude of the correlations between ultrasound and abdominal adipose area, if one were to mistakenly assume that adipose thicknesses and areas are synonymous.

Table 3 shows the comparison of measures with CT-assessed adipose thicknesses. The ultrasound-derived VAT measure was strongly correlated with the CT-derived measure ( $\rho 0.89 ; P<0.0001)$. The ultrasound measure of total SAT was strongly correlated with CT-derived SAT ( $\rho$ 0.93; $P<0.0001)$. Moderate correlations between the ultrasound and CT measures of superficial SAT were observed ( $\rho 0.56 ; P=0.007$ ). The deep SAT compartment was accurately assessed using the corresponding ultrasound measure

Table 3. Correlation coefficients for ultrasound, dual-energy X-ray absorptiometry (DXA) and anthropometric measures of adiposity compared with computed tomography (CT) measures of adipose thicknesses $(n 29)$

\begin{tabular}{|c|c|c|c|c|}
\hline & \multicolumn{4}{|c|}{ CT measure } \\
\hline & $\begin{array}{l}\text { Visceral } \\
(\mathrm{cm})\end{array}$ & $\begin{array}{l}\text { Subcutaneous } \\
\text { (total, cm) }\end{array}$ & $\begin{array}{l}\text { Subcutaneous } \\
\text { (superficial, cm) }\end{array}$ & $\begin{array}{l}\text { Subcutaneous } \\
\text { (deep, cm) }\end{array}$ \\
\hline \multicolumn{5}{|l|}{ Comparative measure } \\
\hline $\mathrm{BMI}\left(\mathrm{kg} / \mathrm{m}^{2}\right)$ & $0 \cdot 61^{\star *}$ & $0.67^{\star *}$ & $0.70^{\star \star \star}$ & $0.72^{\star \star \star \star}$ \\
\hline Waist circumference $(\mathrm{cm})$ & $0 \cdot 67^{\star *}$ & $0.61^{* *}$ & $0.66^{\star \star \star}$ & $0.74^{\star \star \star \star}$ \\
\hline Waist:height ratio & $0 \cdot 64^{\star \star}$ & $0.68^{\star \star}$ & $0.66^{\star \star}$ & $0.74^{\star \star *}$ \\
\hline Ultrasound visceral (cm) & $0.89^{\star \star \star *} \dagger$ & $0.50^{*}$ & $0.50^{*}$ & $0.58^{\star \star}$ \\
\hline Ultrasound subcutaneous (total, cm) & 0.33 & $0.93^{\star * \star *} \dagger$ & $0.79^{\star \star \star \star}$ & $0.82^{\star \star \star \star}$ \\
\hline Ultrasound subcutaneous (superficial, cm) & $0.50^{*}$ & $0.67^{* *}$ & $0.56^{\star}$ & $0.73^{\star \star \star \star}$ \\
\hline Ultrasound subcutaneous (deep, cm) & $0 \cdot 21$ & $0.90^{\star \star \star \star}$ & $0.84^{\star * * *} \dagger$ & $0.87^{\star * \star *} \dagger$ \\
\hline DXA (abdominal fat, $\mathrm{kg}$ ) & $0 \cdot 79^{\star \star \star \star}$ & $0.58^{\star \star}$ & $0.64^{\star \star \star}$ & $0.65^{\star \star}$ \\
\hline DXA (total fat mass, $\mathrm{kg}$ ) & $0.68^{\star *}$ & $0.72^{\star \star \star}$ & $0.76^{\star \star \star \star}$ & $0.78^{\star \star \star \star}$ \\
\hline
\end{tabular}

Lin's concordance correlations $(\rho)$ were used to compare ultrasound and CT measures adjusted for age and sex. Remaining comparisons were made using Spearman's rank-ordered correlations $(r)$ adjusted for age and sex. Correlation $P$ value: ${ }^{*}<0.05,{ }^{*}<0.01$, $\star \star \star * 0.001,{ }^{* \star * *}<0.0001$.

$\dagger$ The strongest correlation for each CT measure. 
( $\rho 0.87 ; P<0.0001)$. None of the Lin's concordance correlations $(\rho)$ differed markedly from the coefficients derived using Spearman's correlation statistic.

Table 4 shows the $\beta$-coefficients, intercepts and $R^{2}$ for the different combination of variables described above.

\section{Assessment of measurement bias}

The analysis of absolute agreement between the ultrasound and CT distance measures revealed a significant mean positive bias for VAT of $0.423(95 \%$ CI $0.079,0.767 \mathrm{~cm} ; P=0.018$; $95 \%$ limits of agreement: $-1.386-2 \cdot 232 \mathrm{~cm}$; RMSE: $0.98 \mathrm{~cm}$ ). The corresponding analysis for SAT revealed a small and nonsignificant mean bias of $-0.034(95 \%$ CI $-0.173,0.104 \mathrm{~cm}$; $P=0.616$; $95 \%$ limits of agreement: $-0.764-0.695 \mathrm{~cm}$; RMSE: $0.36 \mathrm{~cm})$. The RMSE values for these two main adipose compartments amount to $12-14 \%$ of the population mean and to about one-half and one-third of a population SD, respectively.

The subdivision of the SAT compartment was less accurately estimated by ultrasound; ultrasound measured superficial SAT with a non-significant mean bias of -0.098 (95\% CI -0.265 , $0.070 \mathrm{~cm} ; \quad P=0.240 ; 95 \%$ limits of agreement: $-0.891-$ $0.695 \mathrm{~cm}$; RMSE: $0.40 \mathrm{~cm}$ ), whereas the ultrasound-derived deep SAT had a non-significant mean bias of $-0.009(95 \%$ CI $-0.165, \quad 0.147 \mathrm{~cm} ; \quad P=0.904 ; 95 \%$ limits of agreement: $-0.749-0.731 \mathrm{~cm}$; RMSE: $0.36 \mathrm{~cm}$ ). The last two RMSE values amount to $25 \%$ of the population mean and to about one and one-half population SD, respectively.

\section{Discussion}

Here, we compared several body composition assessment methods against CT. The present results agree with previous findings ${ }^{(18)}$ that indicate that a measure of waist circumference can provide an accurate estimate of visceral and subcutaneous adipose areas. For superficial subcutaneous area, BMI yielded the strongest estimate relative to $\mathrm{CT}$. Although waist:height ratio is increasing in popularity ${ }^{(19)}$, this method does not appear to be any better than waist circumference when estimating total subcutaneous or visceral adipose areas. It may, however, provide a better estimate of deep subcutaneous adipose area, which may be relevant to investigators focused on the metabolic or cardiovascular sequelae of abdominal obesity $^{(2-5)}$. In all comparisons, DXA, which is generally considered to be a more accurate method than anthropometry, was either comparably or less strongly correlated with CT-derived adipose areas relative to waist circumference or BMI. This observation may explain why recent studies of obesity genetics have produced disappointing results when using DXA-derived measures of adiposity ${ }^{(16,19)}$.

Several existing studies have sought to derive equations to predict subcutaneous ${ }^{(20,21)}$, intra-abdominal or total abdominal fat mass using ultrasound measurements ${ }^{(21-23)}$. Other studies focusing on absolute validity have reported strong correlations $(r>0.70)$ between ultrasound and intra-abdominal adipose thicknesses when compared with CT and MRI measurements ${ }^{(24)}$. Elsewhere weight:height ratio and ultrasound measures of subcutaneous sagittal diameter adjusted for subcutaneous thickness and intra-abdominal adiposity have been shown to be highly correlated with visceral adipose mass from CT $(r \quad 0.63-0 \cdot 72)^{(25,26)}$. Studies have also been conducted comparing a range of anthropometric measurements (e.g. weight and body circumferences), and they have concluded that sagittal diameter at lumbar 3-5 correlated most strongly with total and visceral adipose volumes assessed by $\mathrm{CT}^{(18)}$.

Table 4. Relationship between computed tomography-assessed adipose compartments (criterion) and measures of basic anthropometry, dual-energy X-ray absorptiometry (DXA) or ultrasound

\begin{tabular}{|c|c|c|c|}
\hline & Equation & $R^{2}$ & RMSE \\
\hline \multicolumn{4}{|c|}{ Visceral adipose $\left(\mathrm{cm}^{2}\right)$} \\
\hline BMI & $10 \cdot 7 \mathrm{BMI}-132$ & 0.16 & 73.9 \\
\hline WC & 6.6 WC -443 & 0.56 & 53.9 \\
\hline DXA (total FM) & $4.4 \mathrm{FM}_{\mathrm{tot}}+41$ & 0.18 & $73 \cdot 3$ \\
\hline DXA (abd FM) & $94.9 \mathrm{FM}_{\mathrm{abd}}-29$ & 0.70 & $45 \cdot 9$ \\
\hline Ultrasound & $37 \cdot 3$ Visceral adipose $e_{\text {us }}-125$ & 0.78 & $37 \cdot 7$ \\
\hline \multicolumn{4}{|c|}{ Total subcutaneous adipose $\left(\mathrm{cm}^{2}\right)$} \\
\hline BMI & $18 \cdot 2 \mathrm{BMI}-257$ & 0.54 & $52 \cdot 1$ \\
\hline WC & $3.5 W C-94$ & 0.17 & $69 \cdot 6$ \\
\hline DXA (total FM) & $7 \cdot 8 \mathrm{FM}_{\mathrm{tot}}+30$ & 0.63 & $46 \cdot 5$ \\
\hline DXA (abd FM) & $60.7 \mathrm{FM}_{\mathrm{abd}}+105$ & 0.32 & $65 \cdot 0$ \\
\hline Ultrasound & $60 \cdot 2$ Subcutaneous adipose us +43.9 & 0.48 & 54.9 \\
\hline \multicolumn{4}{|c|}{ Deep subcutaneous adipose $\left(\mathrm{cm}^{2}\right)$} \\
\hline BMI & $7.8 \mathrm{BMI}-113$ & 0.43 & $27 \cdot 6$ \\
\hline WC & $1.9 W C-81$ & 0.20 & $32 \cdot 6$ \\
\hline DXA (total FM) & $3.1 \mathrm{FM}_{\mathrm{tot}}+15$ & 0.49 & $26 \cdot 1$ \\
\hline DXA (abd FM) & $35 \cdot 6 \mathrm{FM}_{\mathrm{abd}}+26$ & 0.44 & $28 \cdot 3$ \\
\hline Ultrasound & $36 \cdot 9$ Subcutaneous adipose us +27 & 0.48 & $26 \cdot 4$ \\
\hline \multicolumn{4}{|c|}{ Superficial subcutaneous adipose $\left(\mathrm{cm}^{2}\right)$} \\
\hline BMI & $11.6 \mathrm{BMI}-170$ & 0.54 & $32 \cdot 8$ \\
\hline WC & $2 \cdot 1 \mathrm{WC}-56$ & 0.14 & $45 \cdot 0$ \\
\hline DXA (total FM) & $5 \cdot 0 \mathrm{FM}_{\mathrm{tot}}+12$ & 0.71 & $26 \cdot 1$ \\
\hline DXA (abd FM) & $41.7 \mathrm{FM}_{\mathrm{abd}}+55$ & 0.34 & $41 \cdot 0$ \\
\hline Ultrasound & $69 \cdot 8$ Subcutaneous adipose $_{\text {us }}+30$ & 0.35 & $39 \cdot 1$ \\
\hline
\end{tabular}

$R^{2}$, explained variance; RMSE, root mean square error; FM, fat mass; abd, abdominal; WC, waist circumference. 
Several previous studies have examined the validity of ultrasound for adipose thickness quantification. The highest reported correlations emanate from studies where a standardised ultrasound technique was used to determine the distance between the peritoneum and lumbar spine ${ }^{(7,10,11)}$. Two studies have reported almost perfect correlations between ultrasound and CT for SAT and VAT thicknesses $(r 0.96)^{(8,27)}$, whereas others have reported lower correlations for $\mathrm{SAT}^{(9)}$. As we have shown here, the impressive correlations between ultrasound and CT measures of adiposity are predicated largely on the comparison of thicknesses rather than of areas; for the latter, ultrasound yields relatively weak estimates. It is also important to highlight that the limits of agreement for VAT ranged from -1.39 to $2 \cdot 23$. This wide range suggests that the methods may perform well in the setting of a cohort-based analysis, but poorly when used at the individual level. Thus, the appropriate interpretation of these results depends on the setting in which they are to be applied. For example, in studies of metabolic disease or CVD, the total amount of adipose tissue within the specific compartments is likely to be most relevant, whereas the accurate assessment of adipose thicknesses may be more relevant for surgical intervention studies.

One of the novel aims of the present study was to examine the validity of different methods for the assessment of the two subcutaneous compartments. We have shown that BMI, waist: height ratio and DXA (total adipose mass) are strongly correlated with CT-assessed superficial subcutaneous adipose area. For the deep subcutaneous compartment, we have shown that waist:height ratio is the only strong correlate of the respective CT-assessed compartment. This aim was motivated by the independent metabolic characteristics of superficial and deep SAT in the aetiology of cardiometabolic disease ${ }^{(2-5)}$, and by the corresponding need to be able to accurately measure these compartments in epidemiological studies. Although SAT is often considered a metabolically homogeneous tissue, the two subcutaneous compartments have distinct metabolic properties which may influence CVD risk in different ways. In studies of lean and obese glucose-tolerant adults, for example, amounts of visceral and deep SAT were strongly related with metabolic and vascular traits, whereas superficial SAT was not ${ }^{(2)}$. Similar observations have been reported in studies in diabetic and non-diabetic individuals of varying ethnicities ${ }^{(3-5)}$. Thus, assessment methods that are feasible for use in large studies and capable of accurately delineating deep SAT from superficial SAT may have an important role to play when investigating the pathogenesis of obesity. An additional novel aim of the present study was to compare measures of the waist:height ratio, an increasingly popular obesity metric, with other methods of adipose tissue quantification. As outlined above, we have shown that the waist:height ratio is strongly correlated with several of the adipose compartments of interest here, relative to DXA, ultrasound and other anthropometric measures.

The majority of people studied here had a BMI in the normal or overweight range, with only a few obese persons included. Therefore, it is possible that the relationships between the adiposity measures reported here may not generalise to morbidly obese cohorts. It was not possible to assess the reproducibility of the methods in the present study, as repeat measurements were not performed. A further limitation is that only a single CT slice (at lumbar 4) was obtained, which may somewhat influence the validity of the criterion measure owing to intra-subject variability ${ }^{(28)}$.

In summary, simple anthropometric measures of abdominal obesity provided reasonably valid estimates of abdominal adiposity in this population-based cohort of Swedish adults. Neither ultrasound nor DXA, which are more expensive and technically complex than anthropometry, yielded better estimates of adipose area than waist circumference or BMI. The ultrasound measures did, however, provide considerably more accurate measures of adipose thicknesses than the other methods examined here.

\section{Acknowledgements}

We thank the study participants. We also express our gratitude for the expert technical assistance of Lena Uddståhl, Monica Holmgren and the staff of the Clinical Research Center at Umeå University Hospital. The study was funded with grants from the Visare Norr Foundation (to P. W. F.) and the Swedish Heart Lung Foundation (to P. W. F.). P. W. F. was supported in part by a strategic appointment from Västerbotten's health authority (2006-2009). The author contributions are as follows: A. R., E. D. L.-R. and P. W. F. designed the study; A. M. I. G., A. R. and P. W. F. collected data; and A. S. and P. N. processed the CT and DXA data, respectively. S. B. and P. W. F. undertook statistical analyses. A. M. I. G. and P. W. F. wrote the first draft of the manuscript. All authors contributed to data interpretation and revision of the manuscript.

\section{References}

1. Must A, Spadano J, Coakley EH, et al. (1999) The disease burden associated with overweight and obesity. JAMA 282, $1523-1529$.

2. Kelley DE, Thaete FL \& Troost F (2000) Subdivisions of subcutaneous abdominal adipose tissue and insulin resistance. Am J Physiol Endocrinol Metab 278, E941-E948.

3. Koska J, Stefan N, Votruba SB, et al. (2008) Distribution of subcutaneous fat predicts insulin action in obesity in sex-specific manner. Obesity (Silver Spring) 16, 2003-2009.

4. Miyazaki Y, Glass L, Triplitt C, et al. (2002) Abdominal fat distribution and peripheral and hepatic insulin resistance in type 2 diabetes mellitus. Am J Physiol Endocrinol Metab 283, E1135-E1143.

5. Smith SR, Lovejoy JC, Greenway F, et al. (2001) Contributions of total body fat, abdominal subcutaneous adipose tissue compartments, and visceral adipose tissue to the metabolic complications of obesity. Metabolism 50, 425-435.

6. Armellini F, Zamboni M, Rigo L, et al. (1990) The contribution of sonography to the measurement of intra-abdominal fat. J Clin Ultrasound 18, 563-567.

7. Armellini F, Zamboni M, Robbi R, et al. (1993) Total and intraabdominal fat measurements by ultrasound and computerized tomography. Int J Obes Relat Metab Disord 17, 209-214.

8. Padilla S, Gallego JA, Masia M, et al. (2007) Ultrasonography and anthropometry for measuring regional body fat in HIV-infected patients. Curr HIV Res 5, 459-466.

9. Ribeiro-Filho FF, Faria AN, Azjen S, et al. (2003) Methods of estimation of visceral fat: advantages of ultrasonography. Obes Res 11, 1488-1494. 
10. Stolk RP, Wink O, Zelissen PM, et al. (2001) Validity and reproducibility of ultrasonography for the measurement of intra-abdominal adipose tissue. Int $J$ Obes Relat Metab Disord 25, 1346-1351.

11. Tornaghi G, Raiteri R, Pozzato C, et al. (1994) Anthropometric or ultrasonic measurements in assessment of visceral fat? A comparative study. Int J Obes Relat Metab Disord 18, 771-775.

12. Glickman SG, Marn CS, Supiano MA, et al. (2004) Validity and reliability of dual-energy $\mathrm{X}$-ray absorptiometry for the assessment of abdominal adiposity. J Appl Physiol 97, 509-514.

13. Salamone LM, Fuerst T, Visser M, et al. (2000) Measurement of fat mass using DEXA: a validation study in elderly adults. J Appl Physiol 89, 345-352.

14. Jackson S \& Thomas R (2004) Computed tomography (CT): clinical applications of CT. In Cross-Sectional Imaging Made Easy, Chapter 2 [S Jackson and R Thomas, editors]. Oxford: Churchill Livingstone.

15. Tataranni PA \& Ravussin E (1995) Use of dual-energy X-ray absorptiometry in obese individuals. Am J Clin Nutr 62, 730-734.

16. Renstrom F, Payne F, Nordstrom A, et al. (2009) Replication and extension of genome-wide association study results for obesity in 4923 adults from northern Sweden. Hum Mol Genet 18, 1489-1496.

17. Bland JM \& Altman DG (1986) Statistical methods for assessing agreement between two methods of clinical measurement. Lancet 1, 307-310.

18. Kvist H, Chowdhury B, Grangard U, et al. (1988) Total and visceral adipose-tissue volumes derived from measurements with computed tomography in adult men and women: predictive equations. Am J Clin Nutr 48, 1351-1361.

19. Lindgren CM, Heid IM, Randall JC, et al. (2009) Genome-wide association scan meta-analysis identifies three loci influencing adiposity and fat distribution. PLoS Genet 5, e1000508.
20. Ran X, Li X \& Tong N (2003) Estimate of human visceral adipose area and abdominal subcutaneous adipose area in obese Chinese by simple anthropometric parameters. Sichuan Da Хие Хие Вао Yi Хие Ban 34, 519-522, 526.

21. Kekes-Szabo T, Hunter GR, Nyikos I, et al. (1994) Development and validation of computed tomography derived anthropometric regression equations for estimating abdominal adipose tissue distribution. Obes Res 2, 450-457.

22. Hill AM, LaForgia J, Coates AM, et al. (2007) Estimating abdominal adipose tissue with DXA and anthropometry. Obesity (Silver Spring) 15, 504-510.

23. Treuth MS, Hunter GR \& Kekes-Szabo T (1995) Estimating intraabdominal adipose tissue in women by dual-energy X-ray absorptiometry. Am J Clin Nutr 62, 527-532.

24. Vlachos IS, Hatziioannou A, Perelas A, et al. (2007) Sonographic assessment of regional adiposity. AJR Am J Roentgenol 189, 1545-1553.

25. Armellini F, Zamboni M, Harris T, et al. (1997) Sagittal diameter minus subcutaneous thickness. An easy-to-obtain parameter that improves visceral fat prediction. Obes Res $\mathbf{5}$, 315-320.

26. Armellini F, Zamboni M, Castelli S, et al. (1994) Measured and predicted total and visceral adipose tissue in women. Correlations with metabolic parameters. Int J Obes Relat Metab Disord 18, 641-647.

27. Cucchi E, Piatti PM, Orena C, et al. (1997) Is echography an adequate method for assessing the thickness of intra-abdominal fat? A comparison with computed tomography. Radiol Med (Torino) 94, 329-334.

28. Greenfield JR, Samaras K, Chisholm DJ, et al. (2002) Regional intra-subject variability in abdominal adiposity limits usefulness of computed tomography. Obes Res 10, 260-265. 